\title{
Small bowel review: Part II
}

\author{
ABR THOMSON MD PhD FRCPC FACG, JA THOMSON BSc, MJ ROPELESKI MDCM, GE WILD MDCM PhD FRCPC FACP \\ Cell and Molecular Biology Collaborative Network in Gastrointestinal Physiology
}

\begin{abstract}
ABR Thomson, JA Thomson, MJ Ropeleski, GE WiLD. Small bowel review: Part II. Can J Gastroenterol 1996;10(4): 261-273. Major scientific advances have been made over the past few years in the areas of small bowel physiology, pathology, microbiology and clinical sciences. Over 1000 papers have been reviewed and a selective number are considered here. Wherever possible, the clinical relevance of these advances have been identified. Topics discussed are enterocyte proliferation and growth factors; amino acids, peptides and allergies; motility; salt and water absorption and secretion - diarrhea; vitamins and minerals; early development and ageing of the intestine; and ethanol effects.
\end{abstract}

Key Words: Diarrhea, Enterocyte, Ethanol, Growth factor, Motility, Review, Vitamins

\section{Revue de l'intestin grêle : partie II}

RÉSUMÉ : De grands progrès scientifiques ont été accomplis au cours des quelques dernières années dans les domaines de la physiologie et de la pathologie, de la microbiologie et des sciences cliniques appliqués à l'intestin grêle. Plus de 1000 articles ont été passés en revue et une sélection est présentée ici. Dans la mesure du possible, la pertinence clinique de ces progrès a été identifiée. Les thèmes abordés sont notamment la prolifération des entérocytes et les facteurs de croissance, les acides aminés, les peptides et les allergies, la motilité, l'absorption et la sécrétion hydrosodées, la diarrhée, les vitamines et les minéraux, les premiers stades du développement et le vieillissement de l'intestin, et pour terminer, l'éthanol.
$\mathrm{M}$ ajor scientific advances have been made over the past few years in the areas of small bowel physiology, pathology, microbiology and clinical sciences. An in-depth review of the small bowel is presented. Topics discussed are enterocyte proliferation and growth factors; amino acids, peptides and allergies; motility; salt and water absorption and secretion - diarrhea; vitamins and minerals; early development and late ageing of the intestine; and ethanol.

\section{ENTEROCYTE PROLIFERATION AND GROWTH FACTORS}

Small intestinal cell proliferation has been reviewed (1). The structural and functional integrity of the small intestine is maintained by the steady state of cell turnover whereby cell loss from the villi is balanced by cell production in the crypts. Each small intestinal crypt is composed of a single clone of cells, and several crypts contribute to each jejunal villus. The dynamic process of cell proliferation, migration and extrusion results in continuous renewal of the intestinal epithelia about every three days in rodents and every five days in humans. The majority of cells in both the crypt and villus compartments are enterocytes that acquire differentiated functions as they migrate out of the crypt. Migration of enterocytes from crypts to villi is coincident with the appearance of the differentiated phenotype. Little information is available on the molecular mechanisms that regulate cell lineage commitment, cell-specific gene expression or the process of differentiation as cells migrate from crypts to villi.

Trefoil peptides are a group of small peptides that play a role in the process of maintaining the balance between proliferation and cell loss. The peptide is directed to the mucosal surface, in conjunction with mucin and glycoproteins. These trefoil peptides are resistant to protease digestion and

Nutrition and Metabolism Research Group, Division of Gastroenterology, University of Alberta, Edmonton, Alberta; Medical College of St Bartholomew's Hospital, London, United Kingdom; Department of Medicine, Division of Gastroenterology, and Department of Anatomy and Cell Biology, McGill University, Montreal, Quebec

Correspondence: Dr ABR Thomson, University of Alberta, 519 Robert Newton Research Building, Edmonton, Alberta T6G 2C2. Telephone 403-492-6490, fax 403-492-7964, e-mail alan.thomson@ualberta.ca

Received for publication February 20, 1995. Accepted August 14, 1995 
are secreted onto the intestine by goblet cells (2). In situ hybridization of intestinal trefoil factor demonstrates a high degree of expression in mature small intestinal villus and in colonic epithelial goblet cells. There is a high concentration of intestinal trefoil factor in the rough endoplasmic reticulum and in the theca of goblet cells, as well as throughout the mucosal surface (3). Peptides secreted by goblet cells may be taken up from the luminal surface and transcytosed by enterocytes.

A single active multipotent stem cell located near the base of each intestinal crypt sustains stem cell growth and differentiation into four cell types: enterocytes, goblet cells, enteroendocrinal cells and Paneth cells. A novel gutspecific $\mathrm{N}$-myristoylated protein in the annexin-lipocortin family that may affect human intestinal epithelial cell growth has been identified (4). Enhancing factor, a $14 \mathrm{kDa}$ protein, has been isolated from mouse small intestine and has been implicated in cell proliferation (5).

The epidermal growth factor (EGF) receptor is localized primarily to the basolateral enterocyte membrane $(6,7)$. However, localization of the EGF receptor to the brush border membrane (BBM) has been observed in the fetal and suckling rat small intestine (8). EGF promotes DNA synthesis, the transcription of RNA and subsequent protein synthesis. Mucosal exposure to EGF stimulates absorption of intestinal nutrients and electrolytes. In the gastrointestinal tract, EGF is secreted by salivary glands, Brunner's glands of the duodenum and the small intestinal Paneth cells. Secretion is exocrine in fashion, and EGF is present in the gut lumen. Intravenous feeding causes intestinal atrophy, and growth factors in the intestinal juice can be digested by proteases. This degradation can be prevented by the presence of food proteins (1). Recombinant human EGF is a potent stimulator of epithelial cell production in the intestine of adult rats and of humans. In rats fed by total parenteral nutrition, EGF increases both proliferative indexes and the number of dividing cells per crypt (9). The clinical use of EGF remains to be established.

EGF may be able to initiate prematurely molecular changes that occur during normal intestinal development. EGF causes a marked reduction in sucrase activity in Caco-2 cells, whereas other BBM enzymes such as alkaline phosphatase are only marginally affected (10). At low levels EGF affects processing of sucrase-isomaltase (SI) in the endoplasmic reticulum or increases SI degradation, whereas a higher concentration of EGF reduces SI mRNA levels. EGF stimulates cell proliferation and differentiation, and intravenously administered EGF appears in small amounts in bile. EGF reaches the intestine via the lumen, as well as directly on receptors on the basolateral membrane (BLM) (11). Finally, EGF exerts a matrix-specific effect on enterocyte migration by modulation of integrin expression and organization in Caco-2 cells (12).

Transforming growth factor-alpha (TGF- $\alpha$ ) stimulates cell proliferation and is important in promoting cell migration and modulation of fluid and electrolyte transport (13). TGF- $\alpha$ is structurally homologous to EGF, and its action ap- pears to be mediated through the same receptor that binds EGF. TGF- $\alpha$ expression has been detected in the differentiated cells in the upper portions of the crypts and in the villi, but not in the undifferentiated and proliferative cells located near the bottom of the crypts. TGF- $\alpha$ may stimulate growth in an autocrine or paracrine fashion, but TGF- $\alpha$ alone does not have the capacity to transform rat epithelial intestinal cells (14). mRNAs for TGF- $\alpha$, EGF and EGF receptors have been detected in gastric mucosal cells, enterocytes and colonic epithelium. TGF- $\alpha$ receptor binding sites are present throughout the gastrointestinal tract with differential patterns in the various regions, being principally distributed to the mucosa and predominantly located in proliferative cell areas (15).

The TGF- $\beta$ superfamily of growth regulatory molecules includes a large number of polypeptide growth factors that share significant sequence identity and related biological activities. TGF- $\beta$ molecules function in the regulation of cell proliferation and differentiation, stimulation of extracellular matrix synthesis, modulation of cell migration and immunomodulation. Barnard and co-workers (13) reported that TGF- $\beta_{1}$, TGF- $\beta{ }_{2}$ and TGF- $\beta 3$ are closely related molecules that are most prominent in cells located on the villus of rat small intestine, with no activity detected in the crypt. These authors suggest that TGF- $\beta$ molecule "may serve overlapping functions in the intestinal tract, and expression in the epithelium may function to arrest growth of cells emerging from the crypt and induce or maintain the terminally differentiated state". In addition to being a potent inhibitor of proliferation in rat intestinal epithelial monolayers, TGF- $\beta$ may play a role in the reconstitution of epithelial integrity after mucosal injury (16).

Growth hormone has a trophic effect on the intestine via its control of the synthesis and release of insulin-like growth factor I (IGF-1). IGF-1 is delivered to its target tissues by an autocrine or paracrine route. IGF-1 receptors are distributed along the entire length of the rat small intestinal mucosa, and receptor density is higher in crypt than in villus cells. Human recombinant IGF-1 is a potent inducer of the growth-related enzyme ornithine decarboxylase (ODC) in the gut-derived cell line IEC-6 (17).

The roles of polyamines in gastrointestinal mucosal growth (18) and growth factors in the gastrointestinal tract (19) have been reviewed. Polyamines are a class of low molecular weight polycatonic molecules found ubiquitously in biological systems. The polyamines spermidine, spermine and their precursor putrescine have a variety of cellular functions including membrane stabilization, translation processes, regulation of RNA and DNA polymerase activities, regulation of protein kinase activity, transfer of RNA acylation reactions, and cell growth and differentiation. Polyamine transport and de novo biosynthesis appear to be regulated in concert, maintaining intracellular polyamine levels in accordance with cellular needs. The two key enzymes in polyamine biosynthesis are ODC, the initial ratelimiting enzyme, and S-adenosylmethionine decarboxylase (SAMDC). Polyamine synthesis usually precedes DNA syn- 
thesis, and depletion of polyamines attenuates the trophic responses in a number of tissues.

Transglutaminase may be involved in putrescine transport (20). As well, a putrescine uptake system in rat small intestine has been described in isolated enterocytes and in cultured IEC- 6 cells, and this uptake may be regulated by a calcium- and calmodulin-dependent mechanism (21). Exogenous and endogenously synthesized putrescine increase SAMDC activity in a small intestinal crypt cell line, IEC-6 (22). Exogenous polyamines can substitute for endogenous polyamines to support cell migration and mucosal restitution of re-epithelialization (23). Ingestion of food in fasted animals stimulates the release of hormone(s) into the circulation which, in turn, induces mucosal ODC activity and growth. Protein kinase may play an important role in modulating ODC activity (21).

Polyamines regulate the integrity of the intestinal mucosa under a variety of physiological and pathophysiological conditions, and luminal polyamines (at concentrations measured in postprandial chyme) reduce the mucosal injury induced by emulsified dietary lipid (24). This suggests a physiologically relevant role for spermidine in modulating postprandial mucosal injury. Luminal polyamines substitute for endogenously synthesized polyamines in the repair process of the rat duodenal mucosa, and accelerate healing by increasing both an early and a late phase which depend on cell renewal (25).

Inhibition of ODC with alpha-difluoromethylornithine (DFMO) markedly reduces healing in models of mucosal erosion. Oral administration of polyamines immediately after a period of stress increases the normal rate of healing and prevents the inhibition of repair caused by DFMO. This healing process may include restitution, with migration of normal cells into the defective area. The addition of polyamines to an IEC- 6 cell culture model of cell migration restores cell migration to normal (18).

Five-hydroxytryptamine (5-HT) is present in the gastrointestinal tract, located in both enterochromaffin cells and neurons within the enteric nervous system. 5 -HT is a potent secretagogue, increasing short circuit current and thereby enhancing electrogenic chloride secretion. This response is biphasic (26). There are different $5-\mathrm{HT}_{3}$ recognition sites in the rat gastrointestinal tract (27), which is relevant to the potential use of receptor ligands to modify secretory and contraction responses in various portions of the gastrointestinal system.

The tridecapeptide neurotensin (NT) has been identified in the central nervous system (CNS), as well as in the intestinal mucosal $\mathrm{N}$ cells which are located particularly in the mucosa of the distal small intestine. NT stimulates pancreatic and biliary secretions, inhibits small bowel and gastric motility, may exert a systemic effect on the proliferation of proximal gut mucosa and has an indirect effect produced by the stimulation of endogenous luminal secretions (28). Thus, NT has an important enterotrophic role and may prevent gut mucosal hypoplasia such as that induced by feeding rats an elemental diet. In addition, NT is trophic for the gas- trointestinal tract following proximal or distal small bowel resection. There is increased mucosal growth in the remnant intestine, and NT administration augments the adaptive response with both hypertrophy and hyperplasia (29). The clinical use of this observation is awaited.

Plant lectins are present in significant quantities in a variety of legumes and may have an 'antinutritional effect' when fed to humans or animals. When rats are fed purified phytohemagglutinin lectin, there is a trophic response in the jejunum and ileum; this occurs without a change in the plasma or tissue content of gastrin, enteroglucogon or peptide YY (PYY) (30). The interaction between epithelial and mesenchymal tissue is important in the regulation of proliferation and differentiation of intestinal epithelial cells, and mesenchymal cells may be necessary for fetal intestinal epithelial cells to gain full functional differentiation (31).

Ventromedial hypothalamic lesions produce an increase in DNA content in rat intestine, and cell proliferation may be induced by the firing of vagus nerve activity to the cholinergic receptor mechanism (32). Mucin secretion from goblet cells may be increased by cholinergic stimulation, a calcium ionophore or activation of protein kinase $\mathrm{C}$ (PKC) (33).

\section{AMINO ACIDS, PEPTIDES AND ALLERGIES}

The difference along the intestine in the absorption of amino acids is due to a variation of the maximal transport capacity $\left(\mathrm{V}_{\max }\right)$ of the transporters (34). There is a multiplicity of sodium-dependent and -independent transport pathways for amino acids. In rabbit jejunum there is a single high affinity route for the uptake of D-aspartic acid, and both a high and a low affinity process for L-glutamic acid (35). There are three chloride-dependent intestinal transporters of amino acids: the imino, taurine and beta-alanine carriers (36).

The development of the Caco-2 cell line as a model of the intestinal mucosa provides a unique opportunity to study independently both the transmembrane and transcellular transport processes. Efflux of phenylalanine rather than its initial uptake is the rate-limiting step in the cellular transport of this amino acid in Caco-2 monolayers (37). The transport system available for L-threonine in the BBM of pig intestine is functionally distinct from other amino acid transport systems (38). Age-related changes in amino acid uptake respond to alterations in the diet, likely due to a shift in the timing of the genetic program (39). Taurine is a nonprotein amino acid that may be obligatory for the maintenance of high taurine levels in developing animals. HT-29 cells express the taurine transporter, and culture of these cells in the presence of taurine down-regulates this amino acid uptake system (40).

Glutamine plays a key role as an intestinal fuel source and serves as a precursor for the intense nucleotide biosynthesis that accompanies the rapid turnover rate of enterocytes. In Caco-2 cells, glutamine shares the transporter for alanine (41). The intestinal mucosa can obtain glutamine from the blood supply to the enterocytes or from the intestinal lumen, either via extracellular hydrolysis of glutamine-peptide fol- 
lowed by the absorption of glutamine or via the absorption of glutamine-peptide followed by intracellular hydrolysis of these peptides. In human intestine the predominant mechanism for assimilation of glutamine-dipeptide is its absorption as an intact dipeptide (42). In Caco-2 cells there is a strong correlation between the flux of neutral amino acids or neutral peptides, and the total number of $\mathrm{H}^{+}$bonds that these probes can make with water. This suggests that a major impediment to the passive absorption of peptide is the energy required to break the water-peptide $\mathrm{H}^{+}$bonds in order for the solute to enter the cell membrane (43).

The intestinal passage of intact proteins, escaping extraand intra-cell degradation, is of nutritional importance as well as immunological relevance. Gastrointestinal food hypersensitivity has been reviewed (44). Immediate hypersensitivity reactions are a consequence of antigen exposure, resulting in reaginic antibody production and attachment to mast cells. There is subsequent mast cell degranulation and release of mediators, which produce changes such as bronchoconstriction and increased vascular permeability. Immunological reactions to food can involve mechanisms other than immediate hypersensitivity, including immune complex formation and complement deposition. Histamine and prostaglandins (PGs) released from mast cells during antigenic challenge stimulate chloride secretion by activating cholinergic neurons. These use muscarinic synapses for the transfer of signals to the epithelium (45).

The human major histocompatibility complex encodes the class I and class II families of glycoproteins that present peptides for immunorecognition by cytotoxic and helper $\mathrm{T}$ cells. Class I molecules bind peptides generated by degradation of intracellular proteins while class II molecules associate mainly with peptides derived from endocytosed extracellular protein. Two closely linked genes encode subunits of a carrier that transports peptides into an exocytic compartment where they associate with class I molecules (46).

Antigen transport via M cells has been reviewed (47). High dose betamethasone prevents intestinal anaphylaxis in rats immunized with Nippostrongylus brasiliensis (49). The nonsystemic glucocorticoid budesonide, when given before an allergen, dose-dependently inhibits the allergen-induced exudation of plasma into rabbit ileum (49).

\section{MOTILITY}

Myenteric neurons are subdivided into four types based on their electrophysiological behaviour. Patch-clamp recordings in myenteric neurons of guinea pig intestine have demonstrated two populations of neurons: S/type 1 and $\mathrm{AH} /$ type 2. S/type 1, discharged repetitively during injection of depolarizing current, has membrane potentials that are relatively lower and input resistance that is higher than that found for other types of neurons. The second type of myenteric neuronal behaviour is called $\mathrm{AH} /$ type 2 because the action potentials are followed by long duration, hyperpolarizing after-potentials that last for several seconds (50).

Distension of the intestine evokes a stereotyped reflex in which the circular muscle contracts on the oral side of the stimulus and relaxes on the anal side. This peristaltic reflex can be evoked in vitro and is mediated by neurons present within the wall of the gut. The enteric nervous system, which gives rise to this peristaltic reflex, contains intrinsic primary afferent neurons and interneurons, as well as the sensory receptors and motor neurons needed to evoke the reflux behaviour. These separate populations of sensory neurons are necessary to activate reflux pathways. These converge onto common motor neurons and probably onto common interneurons (51). Intrinsic primary afferent neurons are activated by $5-\mathrm{HT}$ acting on the $5-\mathrm{HT}_{1 \mathrm{p}}$ receptor subtype (52). These neurons are probably cholinergic, and co-store calbindin and substance P.

The migrating motor complex (MMC) is a cyclical digestive sequence of motor activity during fasting that is described in three sequential phases. Phase I consists of motor quiescence, and is followed by the irregular contractile activity of phase II, and then a shorter interval of the regular, intense, contractile activity of phase III. Feeding results in replacement of fasting MMC periodicity by an electrical pattern described as the 'fed state'. Factors controlling myoelectric cycling during the fasted state persist after feeding, allowing continuing net aborad propulsion of food (53).

There is an increased expression of interleukin-1-beta (IL-1 $\beta$ ) and mRNA in the myenteric plexus longitudinal muscle region of the gut during the enteric phase of Trichinella spiralis infection in the rat, and IL-1 $\beta$ is a putative mediator of the changes in cholinergic nerve function in this setting (54). IL-1 $\beta$ is a cytokine, and substances released by IL-1 $\beta$ (such as PGs and corticoid trophin releasing factors [CRF]) are involved in the supraspinal control of gastrointestinal motility. The effect of IL-1 on the cecum and colon is mediated by brain CRF, whereas the small intestinal effect is mediated by PGs (55). Two opioid precursors, proenkephalin and prodynorphin, are synthesized in neurons of the myenteric plexus of the gut, and are processed into a variety of active opioid peptides. Opioid agonists have two neurally mediated actions and one direct contractile action on smooth muscles. The distinct $\mathrm{k}, \Delta$ and $\mu$ opioid receptors are present on muscle cells of the circular, but not the longitudinal, muscle layer of the intestine (56).

Neuropeptide Y (NPY) is a 36 amino acid peptide of the pancreatic polypeptide family originally isolated from porcine brain. Centrally administered NPY stimulates feeding and drinking behaviour in the rat, stimulates gastric secretion, and inhibits gastric emptying and intestinal transit (57). This NPY-associated suppression of the movement of solid and liquid meals occurs by stimulation of a betaadrenergic pathway. Beta-adrenal receptors are found on intestinal smooth muscle; beta-antagonists inhibit in vitro contraction of isolated smooth muscle cells and betaantagonists enhance contraction. In human tissue, a betaadrenal receptor-mediated pathway exerts a biologically relevant effect on gut function not only under conditions of sympathetic stimulation, but also at rest when a basal beta- 
adrenergic tone appears to influence the speed of nutrient transit through the human upper gut (58).

NT has both excitatory and inhibitory effects on gastrointestinal smooth muscle. In isolated rat ileal smooth muscle, NT produces a concentration-dependent inhibition of muscular contraction, opening an apamin-sensitive, possibly calcium-activated, potassium channel (59). Nonadrenergic-noncholinergic inhibitory neurotransmitter mediates relaxation of the gastrointestinal tract. Nitric oxide causes relaxation of the circular muscle of rat ileum in a dose-dependent manner and increases the cGMP content of smooth muscle cells (60). Nitric oxide also mediates neural inhibition of circular muscle in both human and canine intestine (61).

$5-\mathrm{HT}$ is a neurotransmitter of the enteric nervous system, and 5-HT-immunoreactive cell bodies and fibres are in the enteric plexuses of the intestine of animals and humans. Enteric 5-HT neurons may regulate gastrointestinal motility by modulating the progression of enteric neurons as interneurons. 5-HT causes ascending contractions by activating $5-\mathrm{HT}_{3}$ receptors in dogs, but activation of $5-\mathrm{HT}_{3}$ receptors can induce an ascending contraction through an enteric excitatory pathway formed by a series of cholinergic interneurons and final cholinergic motor neurons (12). Bile salts delivered into the distal ileum inhibit motor activity of rabbit ileum by an effect that is independent of the release of PYY (63).

The calcitonin gene-related peptide (CGRP), a 37 amino acid polypeptide derived from the calcitonin gene, is present in nerve fibres originating both from extrinsic and intrinsic nerves of the myenteric and submucosal plexus. CGRP is released in the afferent neurons in the gut, and may act as a neurotransmitter or neuromodulator in intramural synaptic pathways in the intestine, resulting in alterations in motility. CGRP induces phasic contractions, thereby increasing contractual activity in the pig ileum (64).

There is considerable intersubject variability in the rate of gastric emptying, as well as in the small intestinal and colonic transit times. Older persons have a slower colonic transit time, but age does not affect gastric emptying or small intestinal transit times (65). The biomagnetic method is a safe, noninvasive and accurate technique for the measurement of segmental oral-to-anal transit time in humans (66). There is considerable variation in the MMC cycle, both between and within subjects; indeed, computer analysis is necessary to provide a standard of reproducibility of human small bowel motility assessment (67).

Motility is altered in inflamed or sensitized intestine, and this inflammation is associated with extensive hyperplasia and hypertrophy of smooth muscle cells (68). Muscle from inflamed colon becomes hyper-responsive to contractile stimuli, whereas muscle from inflamed proximal small intestine generates more tension compared with control muscle. Circular and longitudinal muscles respond differently to inflammation. In Crohn's disease patients there is an increase in maximum contraction induced by carbachol in the longitudinal muscle, whereas in circular muscle there is a marked decrease in the sensitivity to carbachol, with no change in maximum contraction (69).

Cells of the immune system may influence function and/or structure of enteric smooth muscle, or extrinsic or intrinsic nerves, or the release of gut hormones. In rats infected with $T$ spiralis, there is reduced potassium chloridestimulated release of acetylcholine in the jejunum; treatment with betamethasone during the infection prevents the acute inflammatory response and attenuates the suppression of acetylcholine release (70). Marked suppression of acetylcholine release is also seen in $T$ spiralis-infected nude athymic rats which lack functioning $T$ lymphocytes. This suggests that the altered muscle function in this model is $T$ cell-dependent and that different components of the inflammatory response mediate changes in smooth muscle and myenteric nerves.

Viral infection may be a causative factor in neuromuscular disease of the gastrointestinal tract, and a variety of other infective agents have been described including cytomegalovirus (CMV), Epstein-Barr virus, varicella zoster virus, herpes simplex virus, rotovirus and Norwalk virus. Chronic intestinal pseudo-obstruction has been described in association with persistent CMV infection (71). In children, chronic idiopathic intestinal pseudo-obstruction is usually a primary disorder, whereas in adults it is more commonly secondary to diseases such as diabetes mellitus or scleroderma. In one study (72), eight of 11 children with chronic idiopathic intestinal pseudo-obstruction had persistent associated tachygastria.

In approximately $75 \%$ of persons with progressive systemic sclerosis (PSS) there is involvement of the gastrointestinal tract. Motor abnormalities of the distal esophagus are the most common clinical manifestation, followed by disturbances of gastric and intestinal motor function. In patients with PSS and the CREST syndrome (calcinosis, Raynaud's phenomenon, esophageal dysmotility, sclerodactyly and telangiectasa), asymptomatic delay in gastric emptying and colonic transit is common (73).

Smoking and nicotine prolong mouth-to-cecum transit time (74) whereas the calcium channel blocker nifedipine increases orocecal transit time (75). Cisapride facilitates the release of acetylcholine from neural elements within the enteric nervous system, and accelerates gastric emptying, enhances small bowel and colonic transit, and increases the mean contractile amplitude and incidence of distally propagated cluster activity in the small intestine (76). The antidiarrheal action of loperamide is mediated by the opioid receptors (77). Sympathetic nerves release noradrenaline into myenteric axo-axonal synapses which, through postganglionic alpha adrenal receptor stimulation, reduce cholinergic activity in the enteric nerves. Alpha receptors are located on enteric nerves, whereas beta receptors are located on intestinal smooth muscle. Beta adrenergic antagonists speed orocecal transit (58).

In some clinical functional abdominal disorders, symptoms may be directly caused by intraluminal pooling or by distension of the gut, but in other symptomatic patients 
there may be no demonstrable abnormality in gut motility or transit. In these individuals the nociceptive signals appear to arise from physiological stimuli, exciting intestinal afferent pathways and thereby inducing perception in 'visceral hypersensitivity' (78).

Bile salts inhibit the contractor response of the small intestine to a variety of stimuli, including inhibition of motility and delayed transit in humans and in guinea pigs (79). Such bile salt inhibition of excitatory, cholinergic, enteric neurons may slow transit through the ileum, enhancing the time for absorption and thereby conserving the bile salt pool.

A single sublethal dose of radiation abolishes MMC cycling. Fractionated doses of ionizing radiation alter postprandial small intestinal motor activity in the dog, but decrease the mean frequency and duration of duodenal, jejunal and ileal contractions both during and following irradiation (80). It is not known whether abdominal irradiation alters intestinal transit time in humans. Following the development of the acute radiation syndrome in dogs, the myoelectric activity of the jejunum returns to normal. However, after subsequent exposures to 938 cGy abdominal irradiation, the animals develop chronic diarrhea associated with progressive changes in the myoelectric activity, including variable slow waves, an irregular rhythm, reduced spike burst activity, and reduced duration and length of migration (81).

The main site of synthesis of $\mathrm{PGE}_{2}, \mathrm{PGF}_{2 \alpha}$ and thromboxane $\mathrm{B}_{2}$ is in the lamina propria of the intestine, where the sensory mucosal receptors of the submucosal plexors are located. Prostaglandins of the E series contract the longitudinal smooth muscle layer of the small intestine and relax the circular layer, whereas PGs of the F series contract both smooth muscle layers. Although their effects on intestinal smooth muscles are opposite, exogenous PGs of $\mathrm{E}$ and $\mathrm{F}$ series induce diarrhea in humans and animals. $\mathrm{PGF}_{2 \alpha}$ has a direct excitatory effect on intestinal smooth muscle of dogs. This excitatory effect is calcium channel-dependent, but independent of intrinsic nerves. $\mathrm{PGE}_{2}$ has an inhibitory effect on both spontaneous and $\mathrm{PFG}_{2 \alpha}$-induced small intestinal myoelectric and contractile activity (82). Misoprostol, a synthetic $\mathrm{PGE}_{1}$ analogue, shortens orocecal transit time in healthy volunteers (83). Although the effect of $\mathrm{PGF}_{2 \alpha}$ in the dog is calcium channel-dependent, verapamil has no effect on gastric emptying or on ileal filling, but does delay the progression of the colonic geometric centre. This suggests that the constipating effect of verapamil is due to a delay of colonic transit and is not due to an effect on the upper gastrointestinal tract.

The antidiarrheal drug loperamide has a high affinity for -type opioid receptors, and acts on the myenteric plexus and on nerve endings to inhibit the release of both cholinergic and noncholinergic neurotransmitters or neuromodulators. In fasting healthy men, loperamide results in an increased number of contractions, with shortening of phase II (84).

Attempts to alter intestinal motility to improve the symptoms of irritable bowel syndrome (IBS) have been less than successful. Native gonadotropin-releasing hor- mone $(\mathrm{GNRH})$ is a decapeptide that is synthesized and stored in the neurosecretory cells of the medial basal hypothalamus, which are then secreted into the hypothalamicpituitary portal circulation. GNRH initiates secretion of the luteinizing hormones and follicle-stimulating hormone. Luprolide acetate, a potent GNRH analogue, is being proposed to control debilitating symptoms in women with IBS. After ovariectomy, postprandial control in rats treated with low dose leuprolide had typical fed-state patterns and no $\mathrm{MMC}$, but at higher doses of leuprolide the fed-state was inhibited and cycling MMCs occurred at a frequency similar to that of fasted-control. This suggests that this GNRH analogue agonist alters intestinal motility in female rats before and after ovariectomy (85).

Gastrointestinal symptoms occur in most patients with cystic fibrosis, including meconium ileus, distal ileal obstruction syndrome, gastroesophageal reflux disease and intersusception. Intestinal dysmotility may contribute to these symptoms, and there may be abnormalities in the regulatory peptides in children with cystic fibrosis, including increased fasting levels of PYY and an enhanced postprandial response of motilin, enteroglucagon, NT and PYY (86).

In patients with diabetes mellitus, motor abnormalities of the entire gastrointestinal tract are common in both the fasting and the postprandial period. In healthy volunteers rendered hyperglycemic with glucose infusion, there is shortening of the MMC cycle and increased diversion of bile into the gallbladder (87). The hyperglycemia may cause a 'medical vagotomy'; gastrointestinal dysmotility may be associated with disturbances of the sympathetic and parasympathetic pathways supplying the digestive tract, with lesions occurring from the brain to the postganglionic fibres. The extrinsic nervous system appears to have a modulatory role on gut motor function, with primary control being exerted by the enteric nervous system. Performing sympathetic adrenergic and cardiovagal cholinergic function tests in patients with suspected gastrointestinal motility disorders does not add to the diagnostic value of motility tests in distinguishing patients with from those without IBS (88).

The study of human gastroduodenojejunal motility in clinical practice has been reviewed (89), and the technical advances and clinical limitations have been considered (90). Human MMC activity varies widely between individuals, and even within the same individual on different days (91). This variability may limit the demonstration of true differences in MMC between patient groups and controls (92).

In patients with the so-called IBS, prolonged recordings of interdigestive small bowel motility have shown lower diurnal amplitude of phase III activity fronts in constipationpredominant IBS patients than in diarrhea-predominant IBS patients or in controls. In constipation-predominant patients, phase III cycle length is prolonged; in diarrheapredominant patients, repetitive and rapidly propagated bursts of contractions are observed (93). These phase III cyclical bursts occur spontaneously in the small intestine every few hours during fasting, and this cyclical motor activity is preserved in the small intestines of IBS patients. Patients 
with IBS report an abnormal sensation during phase III activity more frequently than do non-IBS patients, suggesting that the threshold for perception of intestinal contraction is lower than normal in at least some IBS sufferers (94).

Psychological stress may be a provoking factor in the alterations in phase II motor activity, although acute psychological stress suppresses rather than enhances duodenojejunal MMC phase II motility in healthy subjects; IBS patients have similar but less marked changes in motility (95). The intermittent nature of the small bowel dysrhythmias in IBS suggest that the biorhythm of phase III in the $\mathrm{MMC}$ cycle in the enteric nervous system is independent of the CNS biorhythm. This CNS biorhythm is characterized by the rapid eye movement (REM) and non-REM sleep cycles; Kumar et al (96) reported no difference between REM latency and a number of REM episodes in the duration of sleep in IBS patients, although the proportion of REM is increased in IBS compared with healthy persons. These authors interpreted their data to be "consistent with the model of IBS as a disorder of brain-gut interaction".

Patients with severe idiopathic constipation often have associated symptoms of bloating, abdominal distension and occasionally vomiting after meals. These symptoms often persist after a subtotal colectomy, and many such patients have a disturbance of gastric and small bowel transit (97). They presumably also have a disturbance in perception.

\section{SALT AND WATER ABSORPTION AND SECRETION - DIARRHEA}

Intestinal electrolyte secretion (98) and acid-base transport systems in gastrointestinal epithelia (99) have been reviewed. Diarrhea caused by defective electrolyte absorption or by excessive electrolyte secretion by intestinal epithelial cells is called secretory diarrhea. The fecal fluid in patients with secretory diarrhea is expected to be rich in electrolytes because the primary cause of the diarrhea is secretion of electrolytes or failure to reabsorb electrolytes. Osmotic diarrhea is caused by the osmotic effect of poorly absorbed solutes that are ingested in the diet or as medications. In patients with osmotic diarrhea, the fecal fluid should be rich in the ingested nonabsorbable solutes and is expected to have a low concentration of electrolytes. In other words, the 'osmotic gap' should be large in patients with osmotic diarrhea and small in those with secretory diarrhea. In experimental diarrhea due to various causes, the osmotic gap is less than $50 \mathrm{mOsm} / \mathrm{kg}$ with secretory diarrhea, but exceeds that value with osmotic diarrhea (100).

$\mathrm{Na}^{+} / \mathrm{K}^{+}$-ATPase is a heterodymeric integral membrane protein located in the BLM of the enterocyte. Villus cells exhibit a higher level of this enzyme than crypt cells, and the villus BLM are more fluid than crypt BLM as measured by 1,6-diphenol-1,3,5-hexatriene (101). The greater fluidity of the villus versus the crypt BLM was associated with an increased phospholipid content of the membrane.

Villus BLM demonstrates two binding sites for ouabain, an inhibitor of $\mathrm{Na}^{+} / \mathrm{K}^{+}$-ATPase, whereas BLM has only a single low affinity binding site. During episodes of diarrhea, glucose-stimulated intestinal sodium absorption remains functional, but glucose must be ingested at concentrations lower than $5 \%$ to prevent osmotic diarrhea. Anthrasene-9-carboxylic acid (A-9-C) stimulates chloride secretion by inhibiting the BBM conductive chloride pathway of the colonic crypt cells. A combination of A-9-C and glucose polymer can reverse dibutyryl adenosine cyclic monophosphate (dbcAMP)-induced intestinal secretion, and this combination produces a better antisecretory effect than D-glucose with A-9-C. This combination awaits clinical testing.

Oral rehydration therapy has been reviewed (102). The World Health Organization (WHO) oral rehydration solution (ORS) has had a major impact on infant morbidity and mortality from diarrhea in the developing world, but its sodium concentration of $90 \mathrm{mmol} / \mathrm{L}$ is considered by some to be too high. In some noncholera types of diarrhea, there is a greater requirement for water than for sodium absorption. Stool volume and thus water loss are reduced if glucose is replaced by a polymeric substrate that reduces osmolality. Using jejunal triple lumen perfusion in healthy adult volunteers, the greatest water absorption was seen with ORS 60:240 (sodium $60 \mathrm{mmol} / \mathrm{L}$, osmolality $240 \mathrm{mOsm} / \mathrm{kg}$ ), and the rates of water absorption with ORS 60:240 were similar to those observed with WHO ORS (103).

Polymers of glucose in similar concentrations can provide the same number of calories as glucose without causing as great an osmotic effect. Rice powder has been used to refine the composition of ORSs and to enhance its performance. Achieving appropriate hydration therapy and proper dietary management can also be achieved by feeding combinations of locally available foods such as cereal or beans (104). Rice, a short glucose polymer, is a better carbohydrate than $2.5 \%$ D-glucose in reversing the secretion of water, chloride and sodium ions induced by dbcAMP in rat small intestine (105). Rice-based ORS has been found to be more effective in reducing stool output, duration of diarrhea and volume of oral rehydration fluid requirement in patients with acute watery diarrhea caused by a variety of agents. Short chain polymers of glucose derived from rice are absorbed faster than glucose, and inhibit the water and electrolyte secretion induced by dbcAMP in the rat small intestine. When glucose in ORS is replaced with glucose polymer from rice, higher areas under the curve of glucose absorption are achieved (105).

Glucose stimulates both active and passive sodium absorption as well as potassium secretion, and glucose derived from maltotriose or glucose oligomer mixture is absorbed faster than from free glucose. In a glucose concentration of up to $6 \%$, water absorption is independent of the type of carbohydrate in the intestinal lumen. Increasing the carbohydrate concentration to $8 \%$ reduces water absorption for solutions containing carbohydrate from three but not seven glucose units or from sucrose (107).

In the fasting state there is net absorption of salt and water in the proximal intestine. The absorption of water and electrolytes from the jejunal lumen increases following the ingestion of a meal, and this meal-induced jejunal absorption 
is mediated by mechanisms independent of the cephalic and gastric phases. A postabsorptive signal for meal-induced jejunal absorption originates from or distal to the stomach, and may involve hemo- or osmoreceptors in stimulating the neurohumoral mechanisms (107). The meal-induced jejunal absorption is stimulated in a calorie-dependent fashion by the intestinal phase of digestion, and the size of this meal-stimulated ileal absorption exceeds the magnitude of meal-stimulated jejunal absorption (109).

Following starvation, incautious refeeding may exacerbate diarrhea, and in severely starved or undernourished persons, death may occur. This exacerbation of diarrhea by refeeding may be partly the result of overloading of the reduced absorptive capacity of the intestine or may be the result of the recent lack of luminal nutrition; there may also be hypersecretion in response to secreted secretagogues stimulation (110). A sipped glucose electrolyte solution appears to be the optimal mode of sodium replacement in patients with a high output jejunostomy (111).

Luminal concentrations of inflammatory mediators increase in certain disease states, such as in patients with inflammatory bowel diseases. This may be due to enhanced synthesis and release of these inflammatory mediators. Histamine stimulates chloride secretion in rat, rabbit and guinea pig intestine, and the lipoxygenase metabolite $\mathrm{LTC}_{4}$ inhibits sodium-chloride absorption and stimulates chloride secretion in rabbit and porcine distal colonic epithelium (112). Intestinal infiltration with inflammatory cells may be associated with mucosal dysfunction and diarrhea, such as occurs in patients with lymphocytic colitis (formerly known as 'microscopic colitis') or in patients with 'pericrypt eosinophilic enterocolitis' (113). The surface mucosal appearance by endoscopy was normal in these patients, and in five of seven patients the diarrhea improved with oral prednisone or prednisone and azathioprine.

Eosinophilia-myalgia syndrome (EMS) is a rare disorder causing generalized myalgias, arthralgias, cough, dyspnea, rash, fever or peripheral edema. Abnormal liver function tests occur in about half of these patients. Radiographic or manometric evidence of abnormal motility has been described in this syndrome, and the onset of diarrhea is often associated with the ingestion of L-tryptophan (114).

Rotaviruses are a major worldwide cause of acute enteritis in infants and small children, and acute rotavirus infection may have a long-lasting effect, evolving into chronic diarrhea. Rotavirus destroys intestinal enterocytes in a patchy fashion, causing partial malabsorption, increased mucosal permeability to antigens and the development of various food intolerances. A transient immunoglobulin (Ig) M and $\mathrm{IgG}$ response is observed during the diarrheal phase, with activation of specific antibody secreting cells against rotavirus (115).

The hydrolysis rate of starch is influenced by its physical and chemical structure, and is modified by the inhibition of pancreatic amylase or of BBM glucosidases. Acarbose, a competitive inhibitor of BBM alpha-glucosidase, inhibits sucrose hydrolysis (and, to a lesser extent, inhibits the degree of starch hydrolysis). Acarbose also inhibits pancreatic alpha-amylase (116). Acarbose may reduce insulin requirements in diabetic patients, possibly by accelerating mouthto-cecal transit time by inducing carbohydrate malabsorption (117).

Substances in the intestinal lumen influence the intestinal absorption of salt and water. In preweaning rats, early dietary antigens delay the development of the gut mucosal barrier (118). This is an important finding because luminal antigens may have an important role in the pathogenesis of several systemic and gastrointestinal disorders (such as cow's milk allergy, celiac disease or inflammatory bowel diseases) that are associated with impaired mucosal barrier function. Cow's milk allergy was once thought to be temporary, but there is now evidence that it may be associated with other allergic symptoms. In patients who have that allergy, an antigenic challenge induces a strong nonantigen-specific immune response that includes a reaction against unrelated antigens concomitantly present in the intestinal lumen (119).

Sorbin is an intestinal peptide isolated from porcine small intestine that induces water absorption, and synthetic peptides containing the $\mathrm{C}$-terminal heptapeptide of sorbin enhance absorption when given in small doses. The clinical usefulness of sorbin has not yet been reported (120).

Molecular biology and hormonal regulation of vertebrate sodium/hydrogen exchanger (NHE) isoforms has been reviewed (121). A major route for sodium and chloride from the human small intestine is through two coupled antiports in the enterocyte BBM: sodium may be exchanged for hydrogen, and chloride may be exchanged for bicarbonate. Defects in these exchangers have been reported, giving rise to diarrhea in the form of congenital sodium-losing diarrhea. A partial defect in the NHE has been described in a young boy in whom the diarrhea resolved after age nine months (122). The activation or inactivation of NHE is rapid, and may be mediated by phosphorylation. Activation of the transporter by serum, alpha-thrombin, EGF or osmotic shrinkage rapidly shifts the intracellular $\mathrm{pH}$ sensitivity of the transporter to more alkaline values. This decreases the affinity for sodium without changing either the affinity of NHE for external sodium or hydrogen, or its $\mathrm{V}_{\max }$. A second and slower class of regulation occurs via an alteration in the $\mathrm{V}_{\max }$ of NHE. The BBM NHE is less sensitive to amiloride than the NHE in some tissues, and is inhibited by calcium, calcium/calmodulin kinase II and PKC. In Caco-2 cells, fetal bovine serum slowly influences the activity of NHE by a process that depends on a post-translational mechanism involving actin polymerization (123).

There are at least three isoforms of NHE in rabbit intestine. NHE-3 has a 10 to 12 membrane-spanning domain, as well as a long cytoplasmic domain which contains putative protein kinase phosphorylation motifs. NHE may be involved in sodium absorption (124). In response to small bowel resection in rats, there is an increase in NHE activity, with activation of an internal modifier site (125). The amiloride-sensitive NHE is present in most, if not all, cell 
types. NHE is present in both the BBM and BLM, and influences cytoplasmic $\mathrm{pH}$ and initiates cell growth and proliferation $(126,127)$. NHE-1 in BLM is important for sodium transport in human jejunal and ileal BLM vesicles (128). The exchangers on the BBM and BLM differ in their sensitivity to amiloride and to potassium (129). The exchanger on the BLM of human jejunum possesses an internal modifier site (130).

In the digestive tract there are cytoplasmic as well as membrane-bound carbonic anhydrases. There are two forms of carbonic anhydrases: one situated in the extracellular leaflet of the BBM and the other one in the intracellular leaflet (131). There is a chloride/bicarbonate exchanger (CHE) in the BLM of rat jejunal enterocytes (132). In villus enterocytes the CHE operates in parallel with a BBM NHE to accomplish net absorption of sodium chloride. In crypt enterocytes the CHE exchanger may play a role in bicarbonate secretion. The polymerase chain reaction has been used to amplify a cDNA encoding an ileal band 3-related protein from rabbit enterocytes; this appears to be a product of the sodium ion exchange gene family (133). In avian intestine, activation of muscarinic receptors stimulates phosphatidylinositol turnover, with release of calcium from intracellular stores and stimulation of calmodulin-dependent protein kinase; this may inhibit NHE (134).

The major difference between the stimulus-secretion pathways activated by phorbol esters down-regulating PKC and by cAMP appears to be in the exploitation of different protein kinases. The PKC-alpha isoenzyme plays a role in both acute stimulation and chronic inhibition of ion secretion in HT-29 colonic cells (135).

The rate of chloride efflux through a BBM conductance channel may be important in controlling the rate of fluid secretion, and perturbation of the control systems for the chloride conductance channel is implicated in disease conditions such as cystic fibrosis (136). In Asiatic cholera $(137,138)$, several proteins with chloride channel activity have been identified, and antibodies have been produced that inhibit chloride conductance in BBM vesicles (139). A clinical use for this has not yet been found. Studies using rat ileal BLM vesicles demonstrate two processes for chloride transport: an electrogenic diffusive process and a second bumetanidesensitive sodium/potassium process (140).

The intestinal sodium-phosphate transporter is electrogenic, transporting two $\mathrm{Na}^{+}$per $\mathrm{H}_{2} \mathrm{PO}_{4}$; tyrosine residues are at or near the cotransporter $\mathrm{Na}^{+}$site, and sulfhydryl residues are important in sodium-phosphate transport. This transporter protein has been purified, and reconstitution studies suggest that it is the sodium-phosphate cotransporter (141). Intestinal uptake of phosphate is increased in diabetic rats (142).

Neuromodulation of ion secretion has been reviewed (143). Acetylcholine, noradrenaline and a variety of small peptides are neuroregulators of epithelial ion transport. Substance $P$ resides in the intestinal neurons, largely originating in the submucous ganglionated plexus, and projects into villus and crypt cells. Substance P alters water and electrolyte secretion in the small and large intestine through an action on enteric neurons (144). CNS control of gastrointestinal activity is responsive to stimulation of vagal afferents, which modulate intestinal water and ion absorption. Intestinal distension increases water absorption in an adjacent noncontinuous segment of bowel distal to the distended segment, and afferent vagotomy prevents this distension effect (145).

Empiric treatment of adults with acute diarrheal disease with norfloxacin is effective in culture-positive patients, those with salmonellosis and severely ill patients, but is less effective than placebo in eliminating salmonella species on days 12 to 17; the opposite was true for Campylobacter species (146). Because norfloxacin has only a modest therapeutic effect, its routine use in patients with acute diarrhea cannot be recommended.

Treatment of infants with bismuth subsalicylate decreases the duration of acute watery diarrheal disease, and is a safe and effective adjunct to oral rehydration therapy (147). Zaldaride maleate is a potent inhibitor of calmodulin activity with gastrointestinal antisecretory properties. In patients with travellers' diarrhea caused by enterotoxigenic Escherichia coli or other bacterial agents, $20 \mathrm{mg} /$ day zaldaride maleate decreases the severity and duration of diarrhea (148). This may prove to be a clinically useful antidiarrheal agent.

\section{VITAMINS AND MINERALS}

Vitamin $D_{3}$ stimulates active calcium transport in the proximal intestine by a three-step process involving the entry of calcium into the enterocyte across the BBM; its translocation across the cytosol; and its active extrusion across the BLM. The uptake of calcium into isolated BBM vesicles of chicks and rats depends on 1,25-dihydroxyvitamin $\mathrm{D}_{3}$ $\left(1,25-[\mathrm{OH}]_{2} \mathrm{D}_{3}\right)$. Calcium uptake is a saturable process that can be inhibited by calcium channel blocking agents. Intestinal calcium absorption is increased during lactation in rats. The rise in duodenal calcium transport in late pregnancy is stimulated by $1,25-(\mathrm{OH})_{2} \mathrm{D}_{3}$, but other factors may be involved such as prolactin. Serum prolactin levels increase markedly between days 18 and 20 of pregnancy in the rat and remain high until at least day seven of lactation. However, serum prolactin levels do not correlate with duodenal calcium transport (149). Furthermore, injecting rat prolactin does not result in a precocious rise in calcium transport in pregnant rats. Although $1,25(\mathrm{OH})_{2} \mathrm{D}_{3}$ stimulates active transepithelial calcium transport in the duodenum, in vivo studies suggest that the bulk of calcium absorption occurs in the distal intestine, particularly in the ileum (a segment that is relatively insensitive to the action of this vitamin). Calcium absorption in the ileum is readily stimulated by nonvitamin D factors such as lactose and bile salts (150). Vitamin $\mathrm{D}$ increases the number of verapamil-sensitive calcium transport components in the BBM (151). 1,25(OH) $2 \mathrm{D}_{3}$ regulates target tissue biological response through genomic events that involve binding of the steroid hormone to the intracellular vitamin $\mathrm{D}$ receptor. Biological actions of $1,25(\mathrm{OH})_{2} \mathrm{D}_{3}$ are correlated with vitamin $\mathrm{D}$ receptor number and occupancy. Intestinal calcium hyperabsorption 
in the idiopathic hypercalciuria rat may be an example of a genetic disorder resulting from a pathological increase in this receptor (152).

Iron homeostasis is maintained primarily by controlling proximal intestinal absorption of dietary iron. The absorptive process involves the uptake of iron across the BBM of intestinal enterocytes, followed by intracellular processing and transfer of iron across the BLM into the portal circulation. The uptake of iron in the proximal intestine depends on cellular metabolism and membrane potential, and exhibits adaptive responses to changes in body iron requirements. The enhancement in duodenal uptake of iron in mice with chronic hypoxia or with iron deficiency parallels the changes in the tissue reduction of $\mathrm{Fe}^{3+}$ to $\mathrm{Fe}^{2+}(153)$. These rates of iron reduction are quantitatively similar to the rates of iron uptake, indicating that a sequential reduction in the uptake process operates for $\mathrm{Fe}^{3+}$ in mouse duodenum. Compared with adult animals, neonates display an enhanced intestinal iron absorption despite substantial body iron storage.

Intestinal iron uptake involves transferrin ( $\mathrm{Tf}$ )-iron binding to the Tf receptor (TfR), with the Tf-TfR complex entering the enterocyte BLM by endocytosis, and with apoTf-TfR recycling after iron is released. Inside the enterocyte iron is stored as ferritin, a multimeric protein composed of heavy and light chains. There is some evidence of Tfmediated iron uptake in the neonatal period. The kinetics of Tf binding by adult duodenal and ileal enterocytes are similar, and are comparable with their respective values in neonatal duodenal ileal cells (154). TfR as well as ferritin $\mathrm{H}$ and $\mathrm{L}$ subunits are key proteins in iron metabolism involved in serum transport, cellular uptake and tissue storage.

Pietrangelo et al (155) analyzed the steady-state levels of Tf and TfR mRNA in gastric and duodenal samples obtained from six normal subjects, 10 patients with anemia, 14 patients with untreated iron overload and eight patients with various gastrointestinal disorders. No Tf mRNA was detected in human gastroduodenal tissue. In normal subjects, higher levels of ferritin $\mathrm{H}$ and $\mathrm{L}$ subunit mRNA were found in duodenal versus gastric samples, but no differences in the content of TfR transcripts were detected. In subjects with iron deficiency there is a dramatic increase in TfR mRNA levels, presumably secondary to a decrease in the cellular iron content, which is also indicated by the low levels of ferritin subunit mRNA. In persons with secondary iron overload, down-regulation of duodenal TfR gene expression and a concomitant increase in ferritin mRNA content is noted. Individuals with idiopathic hemochromatosis have a lack of TfR gene down-regulation and an abnormally low accumulation of ferritin $\mathrm{H}$ and $\mathrm{L}$ subunit mRNA. These molecular abnormalities may be relevant to the metabolic defect of this disease.

The Caco-2 cell line has been used to study the uptake of nutrients. Zinc uptake on the apical side is a saturable process with a diffusional component observed at higher concentrations of zinc (156). Zinc uptake from the basolateral side of Caco- 2 cells is concentration-dependent, and is par- tially inhibited by ouabain and vanadate. Zinc transport from the basolateral side of Caco- 2 cells was more than twice that from the apical cellular membrane. Cloning of rat intestinal mRNAs is affected by zinc deficiency (157).

Biotin is a water-soluble vitamin that is essential for normal cellular functions and development. The vitamin is absorbed from the intestine, and dietary biotin exists in protein-bound and free forms. In meats and cereals, most of the biotin exists in the protein-bound form. This is digested by intestinal proteases and peptidases, which form biocytin and biotin-containing short peptides. Biocytin transport in rat intestine is lower than that of free biotin, and occurs by diffusion so that efficient absorption and optimal bioavailability of dietary protein-bound biotin necessitates its conversion to free biotin (158). Chronic renal failure in rats causes impairment of intestinal biotin transport due do a decrease in the number and/or activity of the biotin transport carriers in the BBM (159).

At low concentrations riboflavin is transported by a saturable, carrier-mediated system, whereas at high substrate concentrations uptake occurs predominately by diffusion. Uptake of riboflavin into BBM vesicles in the presence of a sodium gradient is increased by a valinomycin-induced potassium diffusion potential and by sodium thiocyanate, which increases the intravesicular negative membrane potential (160). Sodium-dependent riboflavin uptake into BBM vesicles is inhibited by structural analogues of riboflavin at low substrate concentrations, and is increased by a low buffer $\mathrm{pH}$.

Monoglutamyl folates exhibit differences in affinity for the intestinal folate transport system and for various folatebinding proteins. In rats, different forms of folic acid exhibit equivalent intestinal absorption, metabolism and in vivo kinetics (161). The intestinal uptake of folate monoglutonate occurs via a carrier-mediated system that recognizes both reduced and oxidized forms of folate, as well the folate antagonist methotrexate. The folate uptake system is driven by a transmembrane $\mathrm{pH}$ gradient and may occur via folic/hydroxyl exchange, folate/hydrogen co-transport mechanism or both (47). Histidine residues are involved in this transport process in the BBM (162).

Vitamin A deficiency results in a sawtooth configuration of the intestinal epithelium, with vesicular microvillar degeneration and disruption of the capillary endothelium; vitamin A repletion minimizes these detrimental effects (163).

\section{EARLY DEVELOPMENT AND LATE AGEING OF THE INTESTINE}

Age-related changes in the intestine occur at the level of digestion and absorption. The ontogenetic development of BBM hydrolysis and of transporters is regulated independently during early development (164). Changes in the BBM enzyme activities coincide with weaning, and represent important alterations to the nutrient differences between milk and solid food. Cortisone, which increases in concentration from the end of the second postnatal week before the time of weaning, is an important factor in intestinal maturation. It has been shown to affect enzyme development in vitro di- 
rectly and through induced precocious maturation of enzyme activity in vivo. Thyroxin also increases in concentration early in the second postnatal week, but thyroxin has not been shown to affect the intestinal epithelium directly. Alterations of thyroid status influence circulating concentrations of both exogenous and endogenous cortisone, due to thyroxin causing increased production of corticosteroidbinding globulin. Thyroxin causes crypt and villus hyperplasia and promotes BBM maturation. In propylthiouraciltreated rats given triiodothyronine, there is marked differential regulation of BBM gene expression, with decreased lactase-phlorizin hydrolase mRNA but unchanged SI levels, and upregulated intestinal alkaline phosphatase mRNA (165). Interestingly, dexamethasone plus thyroxin synergistically increase rat jejunal activities of SI, ileal glucoamalase and duodenal alkaline phosphatase, and lower ileal acid beta-galactosidase (166).

The decline of glucose, galactose and fructose transport into pig intestine from suckling to weaning to early development is due to a combination of reduced transporter site density, shifts in the relative abundances of different monosaccharide transporters and changes in activities of individual transporters. Alterations in the fructose:glucose and galactose:glucose transport ratios before weaning suggest that transporter development is partly genetic (167). In mouse intestine, specific phlorizin binding decreases with age, but there is no age-related change in passive glucose permeability, characteristics of phlorizin binding, transporter turnover rate or the molecular weight of the sodium-glucose co-transporter (168). This suggests that a reduction in glucose transporter site density accounts for the age-related decline in glucose transport rates.

The facilitative glucose transporters comprise a family of structurally related protein. cDNAs encoding five members of this family have been cloned and characterized; there are five facilitative glucose carriers. The fructose transporter in the intestinal BBM is GLUT5, whereas SGLT1 is the BBM sodium-dependent transporter for glucose and GLUT2 is the BLM transporter for glucose and fructose. The mRNAs for SGLT1, GLUT2 and GLUT5 are higher in adult small intestine than in younger animals, whereas the levels of GLUT1 mRNA are higher in fetal than in adult small intestine (158). In the fetal small intestine, GLUT5 is localized along the intercellular junction of the developing villus, whereas GLUT5 is on the BBM of mature enterocytes of adult animals. GLUT5 exhibits selectivity for fructose transport, with a Michaelis-Menten constant of $6 \mathrm{mM}$ (169). In Caco-2 cells GLUT5 is detected in only about $40 \%$ of fully differentiated cells; it is found primarily in the BBM but is also present in both the BLM and intracellular membrane (170). GLUT3 may be the sodium-independent glucose transporter in the BBM of Caco-2 cells. Caco-2 cells express GLUT5 mRNA but not the mRNA for GLUT2 (171). In Caco-2 cells, intestine-specific transcription of the SI gene involves both proximal and distal regulatory elements (172).

During the neonatal period of most mammals, macro- molecules such as $\operatorname{IgG}$ in the colostrum pass intact across the intestinal epithelium. In the rat, this process rapidly disappears when the animal is 20 days old. Repeated oral administration of the synthetic trypsin inhibitor Camostat (in experimental use), which induces negative feedback control of pancreatic enzyme secretion, results in a premature decline in $\operatorname{IgG}$ transport and a precocious increase in maltase activity (173). This effect occurs only with oral and not with subcutaneous administration of Camostat, and the absorptive response of $\operatorname{lgG}$ and maltase activity are not affected by cholecystokinin (CCK) treatment. This suggests that the precocious maturation of the small intestine achieved by oral administration of this synthetic trypsin inhibitor is not mediated by an endogenous release of CCK.

The intestine responds to alterations in the nutrients in the diet. Although aged mice possess adaptive mechanisms to respond to diet changes, the effectiveness of these mechanisms may be impaired compared with younger animals (174). It remains speculative whether the malabsorption that is so prevalent in the elderly may be related to failure of the intestine to adapt normally to changes in the diet.

It has been proposed that there is a 'hard-wired' differentiation program encoded in the intestinal endoderm that does not depend on luminal substances or on hormones for its expression. In situ hybridization analyses reveal that transcription of the genes for rat liver fatty acid binding protein and apolipoprotein AIV genes is activated in the jejunum between fetal days 17 and 18 , yet their expression is not initiated in the ileum until one to two days later (175). It is suggested that initiation of transcription in enterocytes is closely linked to villus morphogenesis and to histological cytodifferentiation.

\section{ETHANOL}

Intraluminal ethanol has been shown to cause morphological and microvascular injury of the mucosa, stomach and intestine, and to increase jejunal absorption of water and solutes. There are villus core contractions and separation of epithelium from the underlying stroma, leading to subepithelial bleb formation. Microvascular injury is characterized by increased arteriolar bloodflow, capillary stasis, increased microvascular permeability to macromolecules and jejunal plasma protein loss (JPPL). Ethanol causes JPPL by inducing release of mediators from mucosal mast cells, and a microvascular injury is directly related to histamine release but not to epithelial damage. JPPL can be attenuated by the administration of 16,16-dimethyl $\mathrm{PGE}_{2}$, which stabilizes mast cells (176). Following acute administration of ethanol, there is also a marked increase in the jejunal recovery of $\mathrm{PGE}_{2}$ (177).

Chronic consumption of ethanol also produces changes in the hydrolytic enzymes in the BBM and alters nutrient transport. Long term ethanol ingestion is often associated with diarrhea, and chronic ethanol intake in rats results in decreased vasoactive intestinal peptide binding to rat enterocytes by reducing the number of binding sites (178).

The point of entry for many gastrointestinal antigens is 
thought to be the membranous cell of the intestinal epithelium. Chronic ethanol consumption results in ultrastructural alterations in ileal membranous cells of rats (179), and this cytopathology is reversible when ethanol exposure is discontinued.

Newborns born of chronic alcoholic mothers often exhibit multiple birth defects that are termed fetal alcohol syndrome (FAS). The daily amount and duration of maternal alcohol ingestion plays an important role in the frequency and severity of these birth defects. When pregnant female

\section{REFERENCES}

1. Lancet $1993 ; 341: 843-8$.

2. Dig Dis Sci 1992;37:716-22.

3. Am J Physiol 1993;264:G179-86.

4. J Biol Chem 1992;267:956-62.

5. Histochemistry 1991;96:367-70.

6. Am Inst Nutr 1992;123:35-41.

7. Gastroenterology 1990;99:370-9.

8. Gut 1992;33:1179-83.

9. Cell Prolif 1992;25:393-404.

10. Am J Physiol 1991;261:C1173-83.

11. Gastroenterology 1992;102:661-7.

12. J Clin Invest 1992;90:15-23.

13. Am J Physiol 1991;261:994-1000.

14. Oncogene 1993;8:1017-22.

15. Dig Dis Sci 1993;38:851-5.

16. Gastroenterology 1993;105:93-101.

17. Am J Physiol 1992;263:E282-6.

18. Am J Physiol 1991;260:G795-806.

19. Gut 1992;33:1297-300.

20. Eur J Physiol 1992;420:329-35.

21. Am J Physiol 1992;263:G742-9.

22. Gastroenterology 1992;102:1109-17.

23. Am J Physiol 1993;264:G367-74.

24. Am J Physiol 1992;263:G224-9.

25. Gastroenterology 1993;104:1692-9.

26. Dig Dis Sci 1992;37:1544-7.

27. Br J Pharmacol 1992;106:693-6.

28. Gastroenterology 1992;103:1254-9.

29. Ann Surg 1992;215:520-6.

30. Gastroenterology 1993;104:1669-77.

31. J Cell Sci 1992;103:511-9.

32. Gastroenterology $1993 ; 104: 475-84$.

33. Dig Dis Sci 1993;38:1046-54.

34. Biochim Biophys Acta 1992;1116:91-6.

35. J Biol Chem 1992;267:1510-6.

36. Am J Physiol 1992;262:G609-15.

37. Biochim Biophys Acta 1992;1135:233-44.

38. J Biol Chem 1992;267:22079-86.

39. Biochem J 1992;285:673-9.

40. Am J Physiol 1993;265:G63-72.

41. Gastroenterology 1992;103:1427-36.

42. Gastroenterology 1992;103:3-11.

43. Pharm Res 1992;9:435-9.

44. Gastroenterology 1992;103:1075-95.

45. Am J Physiol 1992;263:G847-52.

46. Proc Natl Acad Sci USA 1992;89:3932-6.

47. Curr Opin Gastroenterol 1992;8:983-7.

48. Dig Dis Sci 1992;37:1704-8.

49. Scand J Gastroenterol 1992;27:587-93.

50. Am J Physiol 1992;262:G1074-8.

51. J Biol Chem 1989;264:1735-41.

52. J Neurosci 1992;12:235-48.

53. Gastroenterology 1992;103:1817-22.

54. Gastroenterology 1992;104:1648-54.

55. Gastroenterology 1993;104:377-83.

56. Am J Physiol 1992;263:G269-76.

57. Dig Dis Sci 1993;38:845-50.

58. Gut 1992;33:1062-70.

59. Am J Physiol 1992;263:G767-74. rats are fed alcohol, neonatal mortality in the offspring is $28.9 \%$ compared with $0 \%$ for control animals. Even when ethanol is withdrawn at birth, the pups continue to have decreased body weight and decreased intestinal DNA concentration (180). The BBM sucrase activity is lower in alcoholic offspring than in controls, suggesting that the persistence of intestinal injury after birth plays a role in the genesis of the failure to thrive and of the malnutrition observed in infants with FAS.

60. Eur J Pharmacol 1992;216:287-92.

61. Dig Dis Sci 1992;37:198-204.

62. Am J Physiol 1992;263:G306-11.

63. Gut $1993 ; 34: 483-8$.

64. Biochim Biophys Acta 1992;1135:141-6.

65. Dig Dis Sci 1992;37:1548-53.

66. Dig Dis Sci 1992;37:1537-43.

67. Am J Physiol 1993;264:G645-54.

68. Am J Physiol 1992;262:G1041-6.

69. J Nutr 1992;122:2430-9.

70. Am J Physiol 1992;263:G198-201.

71. Dig Dis Sci 1992;37:1761-8.

72. Gut 1992;33:1477-81.

73. Dig Dis Sci 1992;37:1404-8.

74. J Pediatr 1991;118:544-51.

75. Dig Dis Sci 1993;38:1022-5.

76. Dig Dis Sci 1992;37:1569-75.

77. Dig Dis Sci 1993;38:977-95.

78. Am J Physiol 1992;263:G673-7.

79. J Biol Chem 1991;267:7863-70.

80. Dig Dis Sci 1992;37:709-15.

81. Proc Natl Acad Sci USA 1991;88:11017-21.

82. Am J Physiol 1992;263:G488-97.

83. J Neurosci 1992;12:1502-10.

84. Biochem Biophys Res Commun 1992;188:746-53.

85. Am J Physiol 1992;262:G185-90.

86. Dig Dis Sci 1992;37:187-92.

87. Scand J Gastroenterol 1992;27:285-8.

88. Gut 1993;34:397-401

89. Dig Dis Sci 1993;38:785-94

90. Am J Physiol 1992;262:G895-902.

91. Dig Dis Sci 1992;37:723-8.

92. Clin Limitations 1992;37:10-3.

93. Dig Dis Sci 1992;37:168-74.

94. Gastroenterology 1991;101:1621-7.

95. Scand J Gastroenterol 1992;27:53-8.

96. Gastroenterology 1992;103:12-7.

97. Dig Dis Sci 1993;38:837-44.

98. Arch Surg 1993;128:273-8.

99. Gut 1992;33:1134-45.

100. Gastroenterology 1992;103:545-51.

101. Can J Physiol Pharmacol 1992;70:1483-90.

102. J Lab Clin Med 1992;120:471-5.

103. Gut 1992;33:479-83.

104. Pediatrics 1992;90:58-65.

105. Dig Dis Sci 1992;37:20-8.

106. Am J Physiol 1992;263:G248-53.

107. J Appl Physiol 1992;73:2142-50.

108. Gastroenterology 1992;102:486-92.

109. J Surg Res 1992;52:454-8.

110. Gastroenterology 1992;103:29-35.

111. Gut 1992;33:759-61.

112. Am J Physiol 1992;263:G625-31.

113. Gastroenterology 1992;103:168-76.

114. Dig Dis Sci 1992;37:697-701.

115. Gut 1992;33:639-42.

116. Dig Dis Sci 1992;37:1057-664.

117. Gut 1992;33:1246-8.

118. Pediatr Res 1992;32:301-5.

119. Gastroenterology 1993;104:398-409.

120. Gastroenterology 1992;103:1568-73. 
121. J Biol Chem 1992;267:9340-6.

122. J Pediatr Gastroenterol Nutr 1992;15:112-6.

123. Am J Physiol 1992;263:G494-501.

124. J Pharmacol Exp Ther 1993;262:61-6.

125. Am J Physiol 1992;263:G853-63.

126. Eur J Physiol 1992;421:591-7.

127. Am J Physiol 1992;262:G1021-6.

128. Gut 1992:33:1050-6.

129. Am J Physiol 1990;259:G802-6.

130. Am J Physiol 1993;264:G45-50.

131. Biochem Biophys Acta 1992;1109:59-64.

132. Biochim Biophys Acta 1992;1108:140-4.

133. Am J Physiol 1992;263:G345-52.

134. J Cell Physiol 1992;152:362-71.

135. J Membr Biol 1993;135:93-108.

136. Gastroenterology 1992;103:681-93.

137. Gut $1992 ; 33: 1174-8$

138. Gut 1992:33:1652-9.

139. J Membr Biol 1992;129:323-8.

140. Proc Soc Exp Biol Med 1992;201:254-60.

141. Am J Physiol 1993;264:G294-9.

142. Cell Biochem Funct 1992;10:261-6.

143. Physiol Gastrointest Tract 1994;63:2083-120.

144. J Pharmacol Exp Ther 1992;261:1206-12.

145. Gastroenterology 1993;104:916-25.

146. Dig Dis Sci 1992;37:417-25.

147. N Engl J Med 1993;328:1653-8.

148. Infect Dis 1993;16:616-24.

149. Am J Physiol 1992;263:G127-34.

150. Am J Physiol 1993;264:G319-24.
151. Biochim Biophys Acta 1992;1109:187-94.

152. J Clin Invest 1993;91:661-7.

153. J Cell Physiol 1992;152:356-61.

154. Biochim Biophys Acta 1992;1116:256-60.

155. Gastroenterology 1992;102:803-9.

156. Gastroenterology 1991;101:1046-53.

157. Br J Pharmacol 1992;106:877-82.

158. Am J Physiol 1992;262:C795-800.

159. Gastroenterology 1993;104:75-80.

160. J Nutr 1992;122:1454-61.

161. J Nutr 1992;122:1847-54

162. Pediatr Res 1993;33:215-20

163. Dig Dis Sci 1993;38:333-43.

164. Am Rev Physiol 1989;51:601-19.

165. Gastroenterology 1992;103:1529-36.

166. Pediatr Res 1992;32:306.

167. J Biol Chem 1993;268:6694-702.

168. Am J Physiol 1993;264:G285-93.

169. J Biol Chem 1992;267:14523-6.

170. Proc Natl Acad Sci USA 1992;89:7556-60.

171. Am J Physiol 1992;263:G312-8.

172. Ann Intern Med 1992;1:202-8.

173. Am Physiol Soc 1992;263:R996-1002.

174. J Nutr 1993;123:502-11.

175. Scand J Gastroenterol 1992;27:787-92.

176. Am Gastroenterol Assoc 1993;104:361-8.

177. Gastroenterology 1992;102:46.

178. Gen Phamacol 1992;23:607-11.

179. J Stud Alcohol 1992;53:519-23.

180. Pediatr Res 1992;32:574-9. 


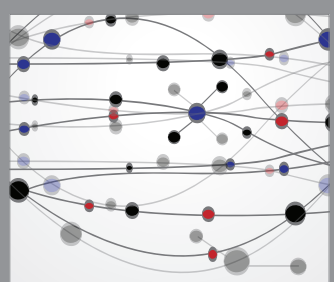

The Scientific World Journal
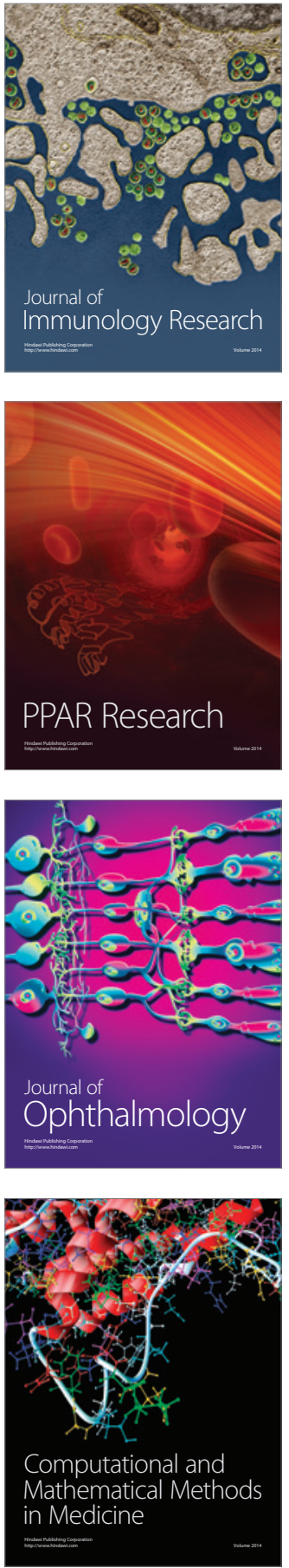

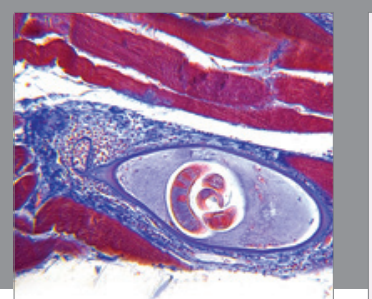

Gastroenterology Research and Practice

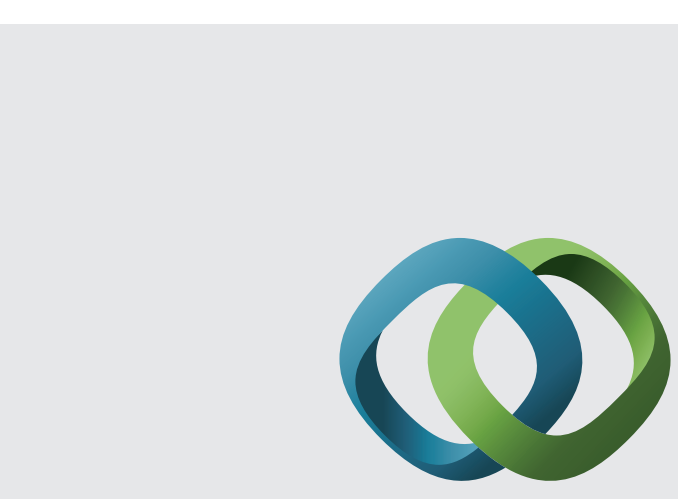

\section{Hindawi}

Submit your manuscripts at

http://www.hindawi.com
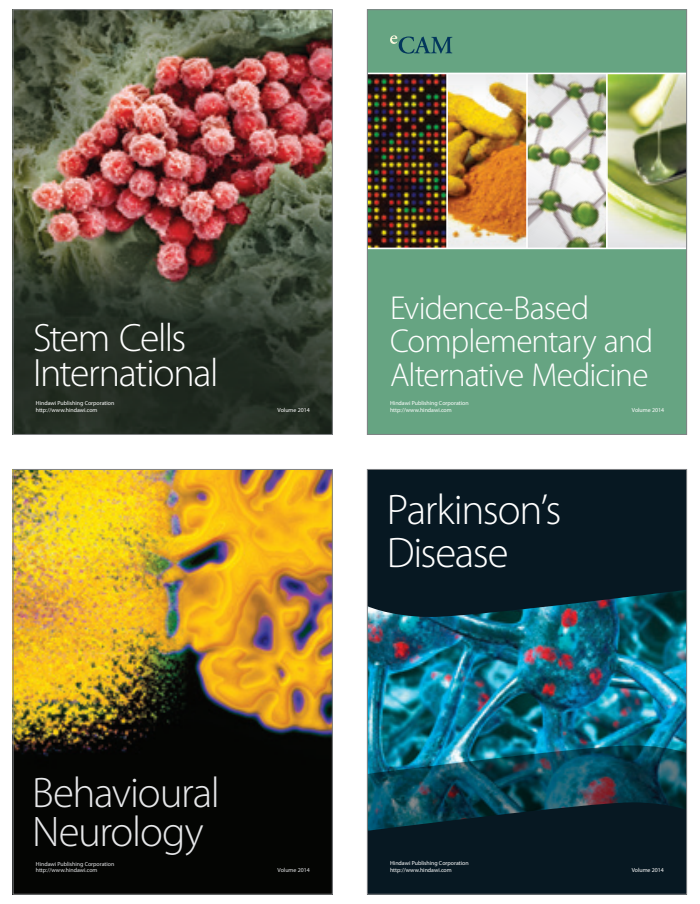
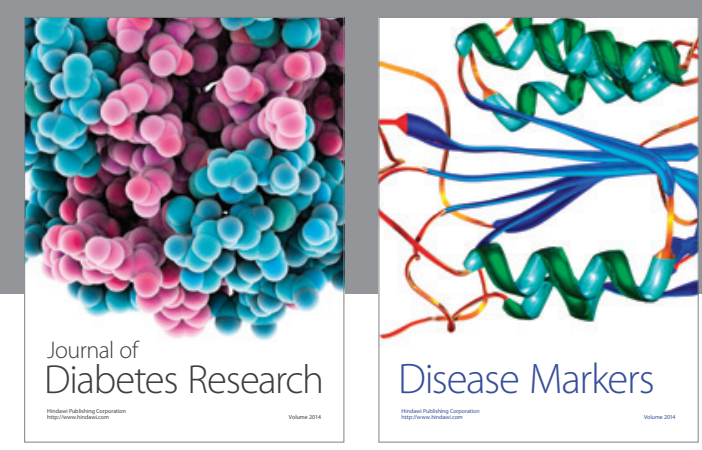

Disease Markers
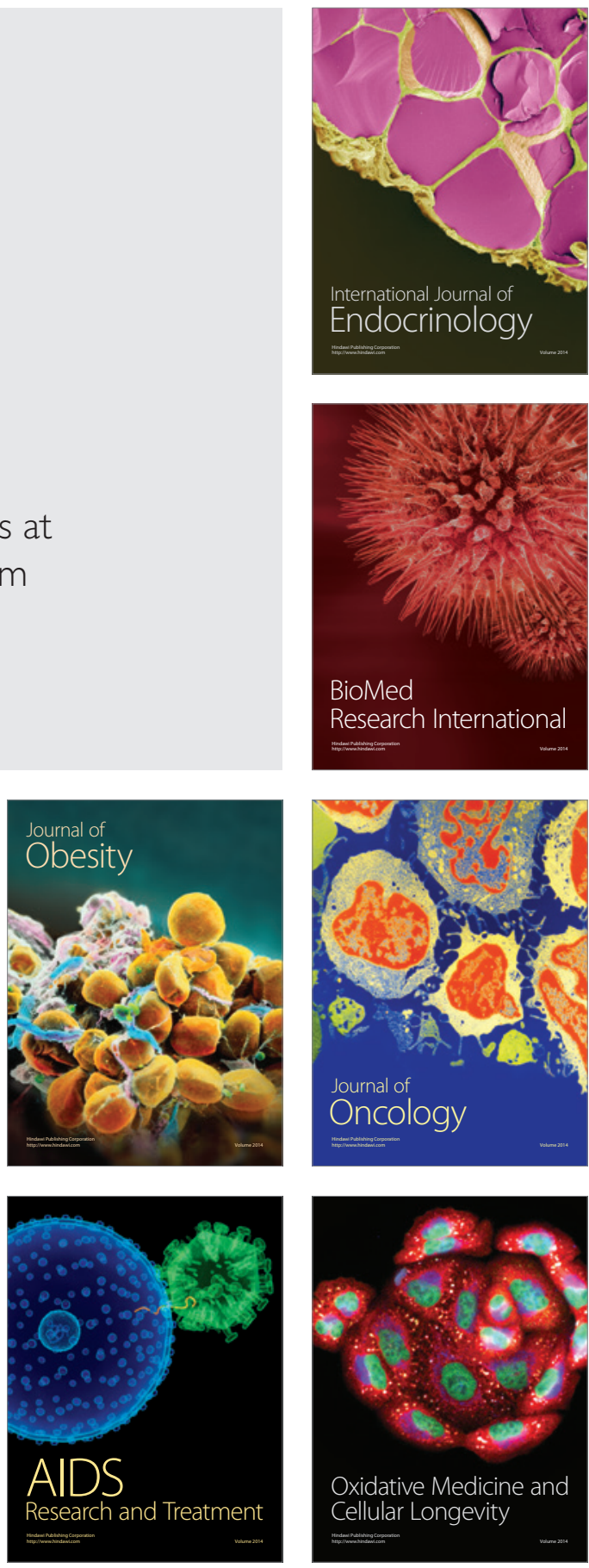